\title{
SOSIALISASI KAWASAN KESELAMATAN OPERASI PENERBANGAN PADA MASYARAKAT KECAMATAN BERINGIN KABUPATEN DELI SERDANG
}

\author{
Hairul Amren ${ }^{*}$, Susi Diriyanti Novalina², Ivana Wardani ${ }^{3}$, Panangian Mahadi Sihombing ${ }^{4}$, \\ Muhammad Yudha ${ }^{5}$, Wiratma Sulistyo Baskoro ${ }^{6}$ \\ 1,2,3,4,5,6 Politeknik Penerbangan Medan Jl. Penerbangan No.85 Jamin Ginting KM.8,5 Medan, Sumatra \\ Utara, 20131 \\ *hairul.amren@gmail.com
}

\begin{abstract}
ABSTRAK. Desa Aras Kabu Kecamatan Beringin termasuk salah satu Kawasan Keselamatan Operasi Penerbangan (KKOP) karena daerah tersebut terletak kurang dari $6 \mathrm{Km}$ dari Bandar Udara Internasional Kualanamu Deli Serdang. Dengan demikian, masyarakat desa tersebut harus membatasi berbagai aktivitas yang dapat menimbulkan bahaya keselamatan penerbangan sesuai dengan regulasi yang berlaku di Indonesia (UU No. 2009 Tentang Penerbangan). Namun, berdasarkan survei Tim Pengabdian Politeknik Penerbangan Medan masih ditemukan beberapa aktivitas masyarakat yang dapat membahayakan keselamatan penerbagan, seperti bermain layang-layang, membakar sampah dan menerbangkan drone. Berdasarkan hal tersebut, maka perlu dilakukan penyadaran kepada masyarakat daerah sekitar. Oleh karena itu, untuk memberikan penyadaran kepada masyarakat maka perlu dilakukan sosialisasi kepada masyarakat agar masyarakat dapat memahami dampak yang dapat ditimbulkan dari kegiatan-kegiatan yang dapat menggangu terhadap aktivitas penerbangan. Politeknik Penerbangan Medan melalui salah satu kegiatan Tridharma Perguruan Tinggi, yaitu kegiatan pengabdian kepada masyarakat telah melakukan sosialisi KKOP di Desa Aras Kabu Kecamatan Beringin Kabupaten Deli Serdang Propinsi Sumaetra Utara. Setalah kegiatan ini dilakukan maka diharapkan terbentuk kesadaran kepada masyarakat terkait peraturan KKOP. Sehingga, hasil kegiatan ini secara tidak langsung diharapkan dapat memperkecil risiko kecelakaan pesawat terbang di kawasan operasi penerbangan
\end{abstract}

Kata kunci: Desa Aras Kabu,, Polteknik Penerbangan Medan

ABSTRACT. Aras Kabu Village, Beringin District, is one of the Aviation Operations Safety Areas (KKOP) because the area is located less than $6 \mathrm{~km}$ from Kualanamu Deli Serdang International Airport. Thus, the village community must limit various activities that can pose a flight safety hazard in accordance with applicable regulations in Indonesia (Law No. 12009 concerning Aviation). However, based on a survey by the Medan Aviation Polytechnic Service Team, there were still some community activities that could endanger flight safety, such as flying kites, burning trash and flying drones. Based on this, it is necessary to raise awareness among the local community. Therefore, to provide awareness to the public, it is necessary to disseminate information to the community so that the public can understand the impact that can be caused by activities that can interfere with flight activities. Medan Aviation Polytechnic through one of the Tridharma Higher Education activities, namely community service activities, has carried out KKOP socialization in Aras Kabu Village, Beringin District, Deli Serdang Regency, North Sumaetra Province. After this activity is carried out, it is hoped that there will be awareness among the public regarding the KKOP regulations. Thus, the results of this activity are indirectly expected to reduce the risk of airplane accidents in the flight operation area.

Keywords: Aras Kabu Village, Medan Aviation Polytechnic

Terima 5 Januari 2022 Terima dan di revisi 7 Januari 2022 Disetujui 10 Januari 2022

\section{PENDAHULUAN}

\section{Kondisi Objektif Lokasi PKM}

Kegiatan Pengabdian Kepada Masyarakat (PKM) ini dilakukan di Desa Aras Kabu Kecamatan Beringin Kabupaten Deli Serdang Provinsi Sumatera Utara. Daerah tersebut dipilih karena berada kurang dari $6 \mathrm{Km}$ dari aktivitas penerbangan Bandar Udara Internasional Kualanamu seperti diperlihatkan pada Gambar 1 dan Gambar 2. Dengan demikian, daerah tersebut merupakan 
Kawasan Keselamatan Operasi Penerbangan (KKOP).

Sehingga, aktivitas penerbangan baik itu pendaratan maupun lepas landas selalu melalui daerah tersebut. Dengan demikian, aktivitasaktivitas masyarakat di kawasan tersebut harus dibatasi sesuai dengan regulasi yang berlaku di Indonesia, yaitu Undang-Undang No. 1 Tahun 2009 Tentang Penerbangan. Hal in dilakukan agar aktivitas-aktivitas masyarakat di daerah tersebut tidak mengganggu aktivitas penerbangan yang dapat membahayakan keselamatan penumpang pada penerbangan sipil (Perhubungan 2019; President and DPR 2009).

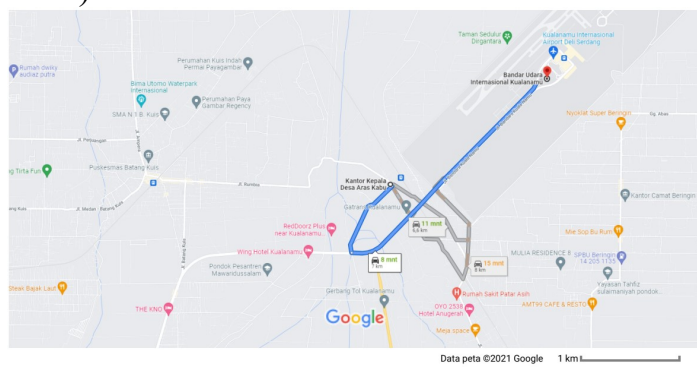

Gambar 1 Peta Desa Aras Kabu Terhadap Bandar Udara Kualanamu (diakses 17.43, 24 Nov. 2021)

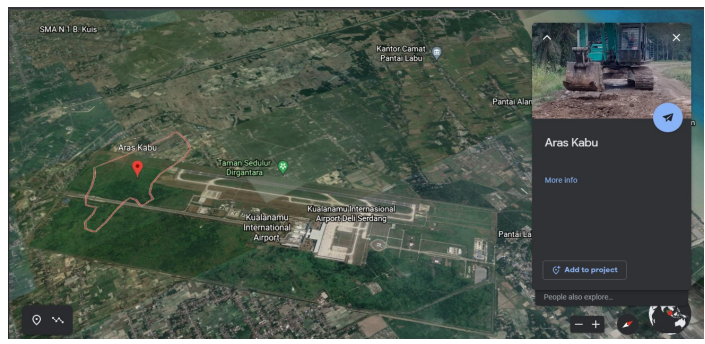

Gambar 2 Tampilan Geografis Desa Aras Kabu. (diakses 17.43, 24 Nov. 2021)

Berdasarkan Gambar 2 dapat diketahui bahwa sebagian besar daerah Desa Aras Kabu adalah daerah pertanian. Selain itu, berdasarkan hasil survei di lapangan yang dilakukan oleh Tim PKM bahwa mayoritas mata pencarian penduduk setempat adalah bertani, berdagang/ jasa dan industri kecil/ kerajinan. Dengan demikian, berdasarkan hal tersebut bahwa Desa Aras Kabu memiliki hambatan (obstacle) yang lebih sedikit untuk aktivitas penerbangan dibandingkan dengan Bandar Udara sebelumnya, yaitu Bandar Udara Polonia Medan.

Berdasarkan Gambar 3 dapat diketahui peta jalur lintasan dari Politeknik Penerbangan Medan ke lokasi PKM Desa Aras Kabu. Jarak tempuh dari Politeknik Penerbangan Medan ke Desa Aras Kabu sejauh 39,7 km dengan waktu yang dapat ditempuh sekitar 54 menit. Struktur pemerintahan Desa Aras Kabu diperlihatkan pada Gambar 4. Berdasarkan gambar tersebut diketahui bahwa Desa Aras Kabu terdiri dari 6 Dusun, yaitu Dusun Amal, Dusun Karya, Dusun Mesjid, Dusun Segitiga dan Dusun Pala

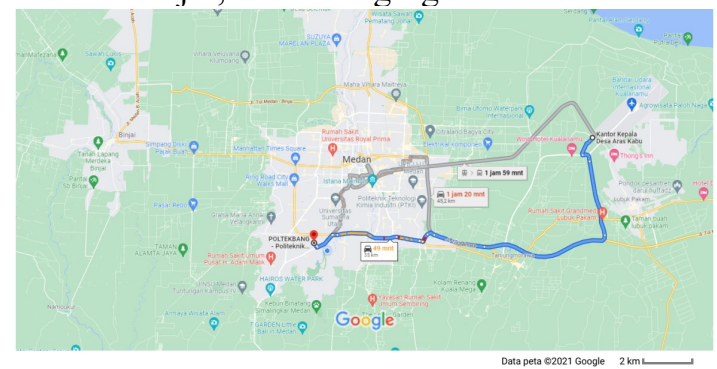

Gambar 3 Peta Perjalanan Politeknik Penerbangan Medan - Desa Aras Kabu Kecamatan Beringin (diakses 17.43, 24 Nov. 2021)

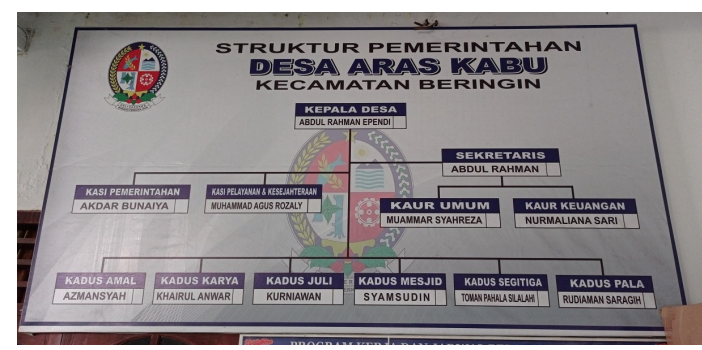

Gambar 4 Peta Perjalanan Politeknik Penerbangan Medan - Desa Aras Kabu Kecamatan Beringin (diakses 17.43, 24 Nov. 2021)

Setiap dusun diatur oleh seorang Kepala Dusun dan seorang Kepala Desa mengatur setiap Kepala Dusun. Kepala Desa dibantu oleh seorang Skretaris dan dua orang Kepala Seksi, yaitu Kepala Seksi Pemerintahan dan Kepala Seksi Pelayanan dan Kesejahteraan. Kemudian, Sekretaris dibantu oleh Kepala Urusan Umum dan Kepala Urusan Keuangan. Nama-nama yang menduduki setiap jabatan struktural diperlihatkan pada Tabel 1.

Tabel 1. Nama Pejabat Struktur Pemerintahan Desa Aras Kabu

\begin{tabular}{|c|c|}
\hline Jabatan Struktural & Nama \\
\hline Kepala Desa & $\begin{array}{l}\text { Abdul Rahman } \\
\text { Efensi }\end{array}$ \\
\hline Sekretaris & Abdul Rahman \\
\hline Kepala Seksi & Akdar Bunaiya \\
\hline Pemerintahan & \\
\hline Kepala Seksi & Muhammad Agus \\
\hline Pelayanan dan & Rozaly \\
\hline Kesejahteraan & \\
\hline Kepala Urusan Umum & Muammar Syahreza \\
\hline
\end{tabular}




\begin{tabular}{ll}
\hline \multicolumn{1}{c}{ Jabatan Struktural } & \multicolumn{1}{c}{ Nama } \\
\hline Kepala Urusan & Nurmaliana Sari \\
Keuangan & \\
Kepala Dusun Amal & Azmansyah \\
Kepala Dusun Karya & Khairul Anwar \\
Kepala Dusun Juli & Kurniawan \\
Kepala Dusun Mesjid & Syamsudin \\
Kepala Dusun Segitiga & Toman Pahala \\
& Silalahi \\
Kepala Dusun Pala & Rudiaman Saragih \\
\hline
\end{tabular}

Peta batas-batas wilayah Desa Aras terhadap wilayah desa lain yang berdekatan diperlihatkan pada Gambar 5. Berdasarkan gambar tersebut dapat diketahui batas-batas Desa Aras Kabu, yaitu sebelah utara berbatasan dengan Desa Serdang, sebelah timur berbatasan dengan Desa Sidourip/ Pasar VI Kualanamu dan sebelah barat berbatasan dengan Desan Tumpatan Nibung/ PT. Perkebunan

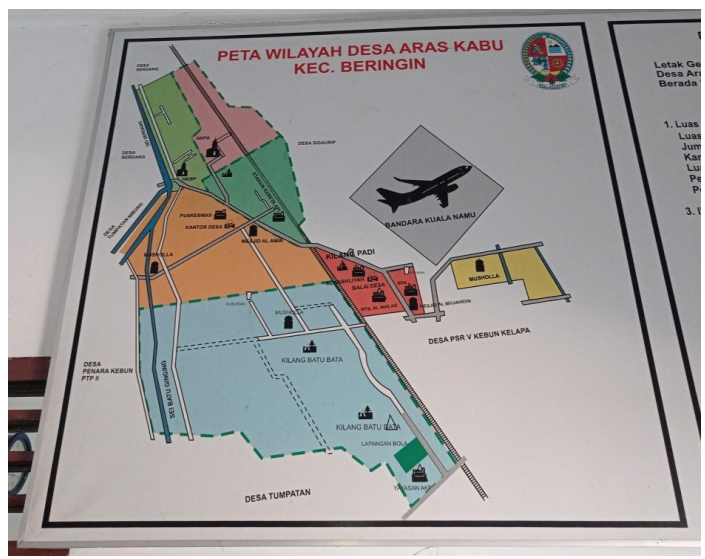

Gambar 5 Peta Wilayah Desa Aras Kabu Kecamatan Beringin

Data umum serta data potensi Desa Aras Kabu Kecamatan Beringin diperlihatkan pada Gambar 6

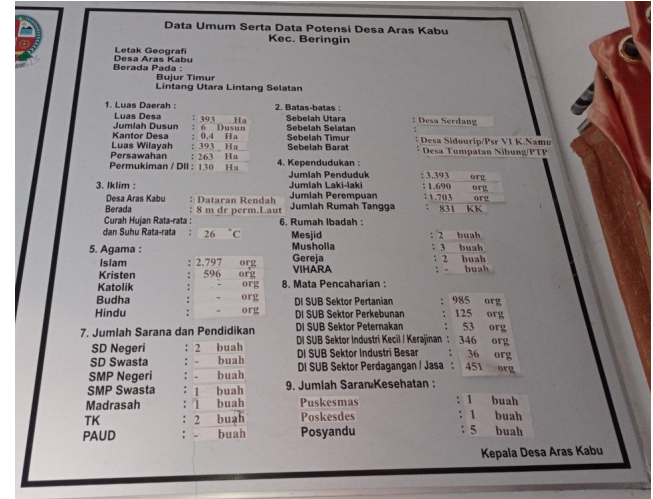

Gambar 6 Data Umum dan Data Potensi Desa Aras Kabu

Berdasarkan gambar tersebut diketahui bahwa Desa Aras memiliki luas daerah sebesar 393 Ha yang berada $8 \mathrm{~m}$ di atas permukaan laut. Desa ini memiliki jumlah penduduk sebanyak 3.393 orang dengan mayoritas beragama Islam. Selain itu, Desa Aras Kabu juga memiliki sarana pendidikan dan sarana kesehatan.

\section{Latar Belakang/ Permasalahan Mitra}

Berdasarkan hasil survei Tim PKM di Desa Aras Kabu Kecamatan Beringin bahwa terdapat beberapa aspek yang harus diperhatikan untuk menjamin keselamatan operasi penerbangan di sekitar area Bandar Udara Kualanamu Deli Serdang. Beberapa aspek tersebut meliputi kondisi bangunan sekitar, pegunungan, perbukitan dan.aktivitasaktivitas masyarakat di sekitar bandar udara yang dapat membahayakan keselamatan penerbangan. Namun, dari beberapa aspek tersebut yang menjadi perhatian utama Tim PKM adalah aktivitas-aktivitas masyarakat yang dapat membahayakan keselamatan penerbangan. Berdasarkan hasil survei Tim PKM telah ditemukan beberapa aktivitas masyarakat yang dapat membahayakan keselamatan penerbangan. Aktivitas-aktivitas tersebut meliputi bermain layang-layang, membakar sampah dan menerbangkan drone. (ICAO 1983; Perhubungan 2010, 2019) Walaupun, tim dari Angkasa Pura telah melakukan sosialisasi KKOP untuk memberikan penyadaran pada masyarakat terhadap aktivitas-aktivitas yang dapat membahayakan keselamatan penerbangan. Namun, masyarakat masih juga melakukan hal yang sama. Hal ini dapat disebabkan oleh beberapa keterbatasan, yaitu:

a. Keterbatasan Pemahaman 
Masih ada masyarakat Desa Aras Kabu Kecamatan Beringin yang belum memahami KKOP dan bentuk kegiatan beresiko tinggi terhadap zona keselamatan Penebangan.

b. Keterbatasan Waktu

Mayoritas masyarakat Desa Aras Kabu Kecamatan Beringin sangat sibuk dengan kegiatan pekerjaan sehari-hari. Sehingga, mayoritas masyarakat terpikir untuk mengetahui aktivitas-aktivitas yang dapat membahayakan keselamatan penerbangan.

c. Kekecewaan Masyarakat

Kekecewaan masyarakat Aras Kabu Kecamatan Beringin bermula dari lambannya penanganan pihak bandar udara dalam menangangi kerugian yang dialami oleh beberapa masyarat. Kerugian yang terjadi adalah seng/ atap rumah masyarakat yang terbang akibat pesawat terbang yang melintas rumah penduduk dengan cukup rendah.

Solusi

Berdasarka latar belakang permasalahan tersebut maka diperlukan usaha penyadaran kepada masyarakat di sekitar bandar udara terhadap aktivitas-aktivitas yang dapat membahayakan keselamatan penerbangan. Selain itu, diperlukan juga penyadaran masyarakat terkait prosedur pelaporan kerugian yang dialami masyarakat akibat adanya bandar udara. Dengan demikian, masyarakat memahami prosedur pelaporan sehingga dapat meningkatkr kesadaran masyarakat terhadap aktivitas-aktivitas yang dapat membahayakan keselamatan penerbangan. Untuk mecapai hal tersebut, maka Tim PKM telah merangkum solusi yang ditawarkan dalam menyelesaikan permasalahan yang dihadapi masyarakat Desa Aras Kabu Kecamatan Beringin, yaitu:

a. Sosialisasi terkait dampak positif dan negatif keberadaan Bandar Udara Internasional Kualanamu bagi masyarakat Desa Aras Kabu Kecamatan Beringin Kabupaten Deli Serdang Provinsi Sumatera Utara. (Narasumber 1)

b. Sosialisasi KKOP kapada masyarakat Desa Aras Kabu, yang meliputi UU No. 1 Tahun 2009 tentang penerbangan dan regulasi lainnya terkait KKOP. (Narasumber 2)

c. Sosialisasi terkait keseimbangan antara pengelolalaan operasional bandar udara dengan kehidupan masyarakat sekitar dalam perspektrif hukum lingkungan.(Narasumber 3)

\section{Target Luaran}

Target luaran yang diharapkan dari hasil kegiatan PKM di Desa Aras Kabu Kecamatan Beringin adalah:

a. Masyarakat mengetahui bahwa Bandar Udara tidak hanya berdampak negatif yang umumnya dirasakan oleh Masyarakat Aras $\mathrm{Kabu}$, melainkan juga terdapat dampak positif yang dapat dirasakan oleh masyarakat maupun perhatian yang diberikan oleh pengelola bandar udara. Dengan demikian, diharapkan dapat menimbulkan kesadaran kepada masyarakat terkait KKOP.

b. Masyarakat memahami aktivitas-aktivitas masyarakat di sekitar bandar udara (KKOP) yang dapat membahayakan keselamatan penerbangan.

c. Masyarakat memahami dalam hal keseimbangan antara pengelolalaan operasional bandar udara dengan kehidupan masyarakat sekitar dalam perspektrif hukum lingkungan.

\section{METODE}

Metode pendekatan yang dilakukan oleh Tim PKM adalah metode ceramah dan diskusi. Metode ceramah dan diskusi kepada masyarakat dilakukan menggunakan alat bantu audio visual berupa proyektor dan sound system. Dengan demikian, masyarakat diharapkan dapat secara maksimal memahami materi sosialisai yang diberikan. Materi sosialisasi pada program ini meliputi:

1. Ceramah terkait profil Politeknik Penerbangan Medan (Poltekbang Medan). Pada bagian ini dijelaskan tentang posisi keberadaan Politeknik Penerbangan Medan serta bentuk-bentuk aktifitas pendidikan yang dilaksanakan oleh Taruna/taruni Politeknik Penerbangan Medan maupun kegiatan kegiatan seperti Tridharma Perguruan Tinggi. Materi ini disampaikan oleh ketua Tim PKM, yaitu Bapak Hairul Amren Samosir, S.Sos., M.Pd. yang merupakan salah satu dosen di Politeknik Penerbangan Medan.

2. Ceramah terkait dampak positif dan negatif keberadaan Bandar Udara Internasional Kualanamu bagi masyarakat 
Desa Aras Kabu Kecamatan Beringin

Kabupaten Deli Serdang Provinsi Sumatera Utara. Kegiatan ini disampaikan oleh Kepala Desa Aras Kabu Kecamatan Beringin, yaitu Bapak Abdul Rahman Efendi.

3. Ceramah terkait kawasan keselamatan operasi penerbangan (KKOP) disampaikan oleh Bapak Arif Zulfahri Siregar, Amd berasal dari Airnav Bandar Udara Kualanamo. Pada bagian ini dijelaskan terkait regulasi yang mengatur tentang perlindungan hukum terhadap kawasan penerbangan dan pembatasan aktivitasaktivitas masyarakat di kawasan penerbangan untuk menjamin keselamatan penerbangan. Bapak Arif Zulfahri Siregar, Amd. Beliau juga merupakan alumni Politeknik Penerbangan Medan dan juga sebagai teknisi yang bekerja di Bandar Udara Internasional Kualanamu.

4. Ceramah terkait keseimbangan antara pengelolalaan operasional bandar udara dengan kehidupan masyarakat sekitar dalam perspektrif hukum lingkungan. Pada bagian ini disampaiakan oleh Dr. Novi Juli Rosani Zulkarneaen, S.H., M.H. Ibu Dr. Beliau merupakan seorang praktisi hukum dan juga dosen Pasca Sarjana di salah satu Universitas Kota Medan.

\section{HASIL DAN PEMBAHASAN}

Pelaksanaan kegiatan pengabdian kepada masyarakat dengan tema Sosialisasi Kawasan Keselamatan Operasi Penerbangan pada Masyarakat Kecamatan Beringin Deli Serdang telah dilakukan pada Tanggal 16 Oktober 2021. Kegiatan ini dilakukan selama 1 hari, yaitu mulai pukul 08.00 - 17.00 WIB. Adapun tata tertib kegiatan ini diperlihatkan pada Tabel 2 berikut.

Tabel 2. Tata Tertib Kegiatan Pengabdian Kepada Masyarakat

\begin{tabular}{cl}
\hline $\begin{array}{c}\text { Waktu } \\
\text { (WIB) }\end{array}$ & \multicolumn{1}{c}{ Program } \\
\hline $08.00-09.00$ & $\begin{array}{l}\text { Pembukaan program Pengabdian } \\
\text { Kepada Masyarakat Politeknik } \\
\text { Penerbangan Medan. }\end{array}$ \\
Kata sambutan oleh Kepala Desa \\
& $\begin{array}{l}\text { Aras Kabu Kecamatan Beringin } \\
\text { Kabupaten Deli Serdang } \\
\text { Provinsi Sumatera Utara. }\end{array}$ \\
& \\
\hline $10.00-10.15$ & Break (Snack)
\end{tabular}

\begin{tabular}{|c|c|}
\hline $\begin{array}{l}\text { Waktu } \\
\text { (WIB) }\end{array}$ & Program \\
\hline $10.15-12.00$ & $\begin{array}{l}\text { Sosialisasi } \\
\text { Keselamatan } \\
\text { Penerbagan }\end{array}$ \\
\hline $12.00-13.30$ & Break (Makan Siang) \\
\hline $13.30-14.00$ & $\begin{array}{l}\text { Sosialisasi } \\
\text { Keselamatan } \\
\text { Penerbagan lanjutan }\end{array}$ \\
\hline $14.00-15.00$ & $\begin{array}{l}\text { Sosialisasi keseimbangan antara } \\
\text { pengelolalaan operasional } \\
\text { bandar udara dengan kehidupan } \\
\text { masyarakat sekitar dalam } \\
\text { perspektrif hukum lingkungan }\end{array}$ \\
\hline $15.00-15.15$ & Break (Snack) \\
\hline 15.1 & $\begin{array}{l}\text { Sosialisasi keseimbangan antara } \\
\text { pengelolalaan operasional } \\
\text { bandar udara dengan kehidupan } \\
\text { masyarakat sekitar dalam } \\
\text { perspektrif hukum lingkungan }\end{array}$ \\
\hline $16.30-17.00$ & $\begin{array}{l}\text { Penutupan program Pengabdian } \\
\text { Kepada Masyarakat Politeknik } \\
\text { Penerbangan Medan }\end{array}$ \\
\hline
\end{tabular}

Pembukaan program pengabdian kepada masyarakat dilakukan oleh ketua pelaksana, yaitu Bapak Hairul Amren Samosir, S.Sos., M.Pd. Namun, sebelum pembukaan program kegiatan pengabdian tersebut dimulai, seluruh peserta berdiri untuk mendengarkan lagu Indonesia Raya seperti diperlihatkan pada Gambar 7, Gambar 8 dan Gambar 9

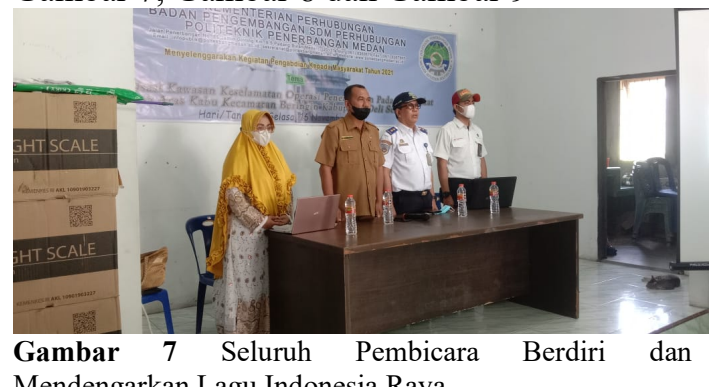

Mendengarkan Lagu Indonesia Raya

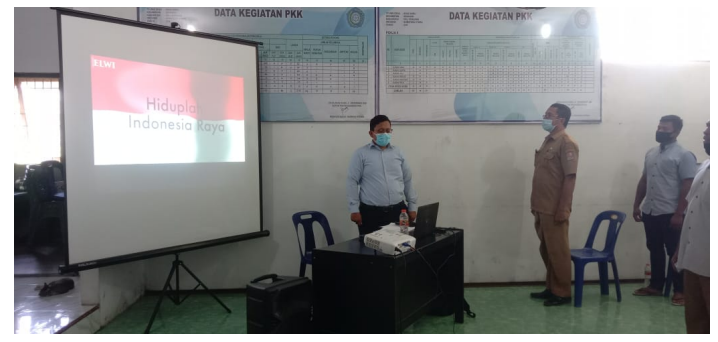

Gambar 8 Protokol Mendengarkan Lagu Indonesia Raya

Kegiatan pengabdian kepada masyarakat ini dilakukan di Ruang Serbaguna Kantor Kepala Desa Aras Kabu Kecamatan Beringin 
Kabupaten Deli Serdang Provinsi Sumatera Utara. Kegiatan ini mendapat dukungan baik oleh Kepala Desa beserta staf jajarannya dan masyarakat Desa Aras Kabu. Kegiatan ini terdiri dari empat narasumber, seorang protocol dan 20 orang peserta. Seluruh peserta terdiri dari Kepala Dusun, Babinsa, dan masyarakat setempat. Selama mendengarkan Lagu Indonesia Raya seluruh hadirin berdiri tegak seraya menghayati pengorbanan para pahlawan yang telah gugur

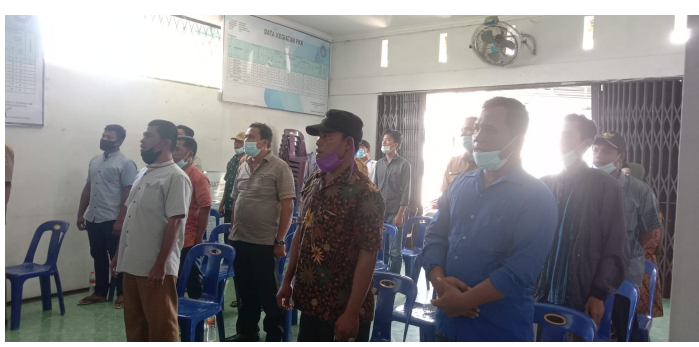

Gambar 9 Pesertia Mendengarkan Lagu Indonesia Raya

Kata sambutan oleh ketua pelaksana kegiatan pengabdian masyarakat Politeknik Penerbangan Medan oleh Bapak Hairul Amren Samosir, S.Sos., M.Pd. diperlihatkan seperti pada Gambar 10 berikut.

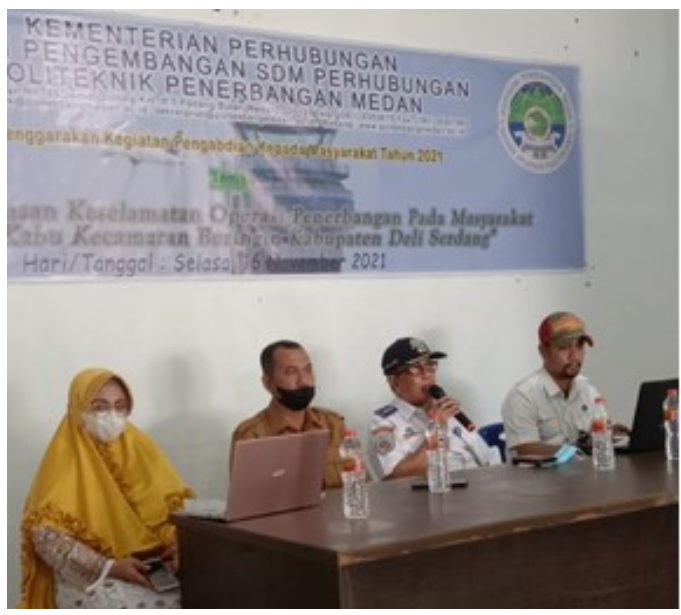

Gambar 10 Kata Sambutan oleh Ketua Pelaksana Kegiatan Pengabdian Masyarakat Politeknik Penerbagan Medan

Kata sambutan oleh ketua pelaksana kegiatan pengabdian masyarakat Politeknik Penerbangan Medan meliputi penyampaian tujuan kegiatan sosialisasi yaitu sebagai berikut:

a. Melaksanakan kegiatan pengabdian kepada masyarakat merupakan salah satu kewajiban di dalam Tridharma Perguruan Tinggi yang harus dijalankan. Kegiatan
Tridharma yang lain adalah melaksanakan pendidikan dan penelitian. Pada kesempatan tersebut, disampaikan bahwa sosialisasi KKOP ini adalah dalam rangka memberikan pemahaman kepada masyarakat tentang Kawasan Keselamatan Operasi Penerbangan, baik itu Hak maupun Kewajiban Masyarakat yang tinggal diarea dimaksud

b. Memperkenalkan profil Politeknik Penerbangan Medan kepada masyarakat di Desa Aras Kabu Kecamatan Beringin Kabupatn Deliserdang.

Kata sambutan oleh Kepala Desa Aras Kabu Kecamatan Beringin Kabupaten Deli Serdang Provinsi Sumatera Utara, yaitu Bapak Abdul Rahman Efendi diperlihatkan seperti pada Gambar 11.

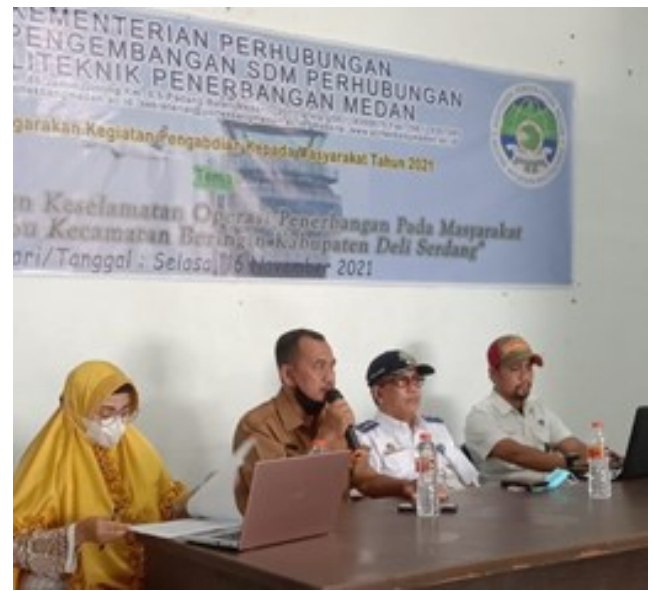

Gambar 11 Kata Sambutan oleh Kepala Desan Aras Kabu

Selain menyampaikan kata sambutan, Kepala Desa Aras Kabu juga berperan sebagai narasumber untuk materi dengan tema "Dampak Positif dan Negarif Kebaradaan Bandar Udara Internasional Kualanamu Bagi Masyarakat Desa Aras Kabu Kecamtan Beringin". Materi inti pada kegiatan ini, yaitu Sosialisasi Kawasan Keselamatan Operasi Penerbangan disampaikan oleh Arif Zulfahri Siregar, Amd seperti diperlihatkan pada Gambar 12 berikut 


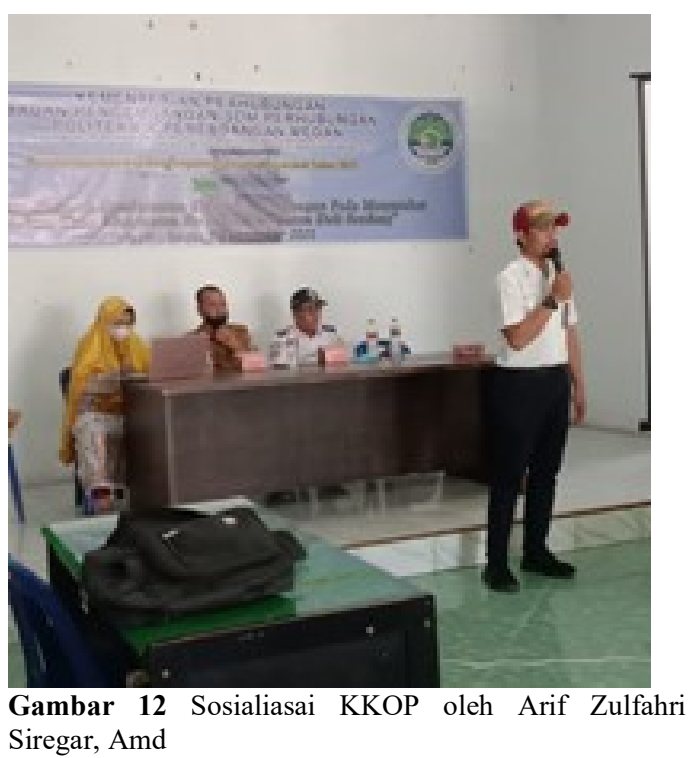

Penyampaian materi terkait KKOP oleh Bapak Arif Zulfahri Siregar, Amd adalah sebagai berikut:

a. Penjelasan singkat terkait dasar hukum KKOP di Indonesia.

b. Penjelasan terkait definisi dan fungsi KKOP

c. Penjelasan terkait ketentuan bangunan/ benda tumbuh di KKOP, dan

d. Penjelasan terkait bahaya yang ditimbulkan akibat aktivitas masyarakat di KKOP seperti menebangkan layanglayang, lampion, drone dan balon udara. Selain itu, permainan lampu laser yang dapat juga menimbulkan bahaya bagi penerbangan.

Materi dengan tema "Keseimbangan Antara Pengelolalaan Operasional Bandar Udara dengan Kehidupan Masyarakat Sekitar dalam Perspektrif Hukum Lingkungan" disampaikan oleh Ibu Dr. Novi Juli Rosani Zulkarneaen, S.H., M.H. seperti diperlihatkan pada Gambar 13 berikut.

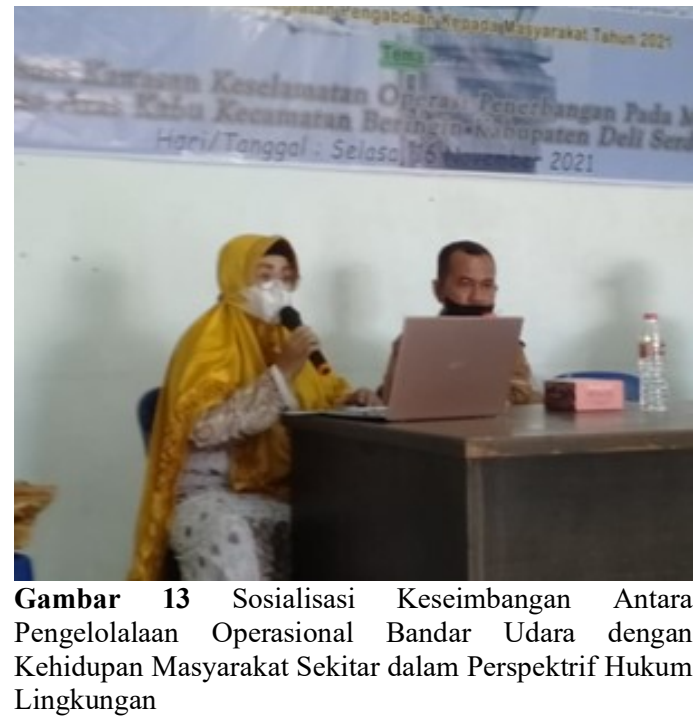

Penyampaian materi dengan tema "Keseimbangan Antara Pengelolalaan Operasional Bandar Udara dengan Kehidupan Masyarakat Sekitar dalam Perspektrif Hukum Lingkungan" meliputi:

a. Dasar hukum terkait penyelenggaraan bandar udara di Indonesia

b. Prosedur secara hukum terkait pengaduan masyakat terhadap pengelola operasional bandar udara akibat kerugian yang diakibatkan oleh lalu lintas pesawat udara.

Setelah setiap materi telah disampaikan oleh setiap narasumber, salah seorang peserta memberikan beberapa pertanyaan dan keluhan diperlihatkan pada Gambar 14. Beberapa pertanyaan dan keluhan tersebut sebagai berikut:

a. Pesawat udara yang melintas di desa kami sering menerbangkan seng/ atap rumah kami. Dan setelah kami melapor Kepala Desa dan meneruskannya ke pihak bandara, namun penanganan yang dilakukan oleh pihak bandara sangat lambat karena kalau seng kami terbuka maka air hujan kapan saja bisa masuk ke dalam rumah. Selain itu, penanganan juga tidak memuaskan karena pihak bandara hanya mengganti seng yang rusak akibat diterbangkan, namun tidak memberikan jasa pemasangan seng 


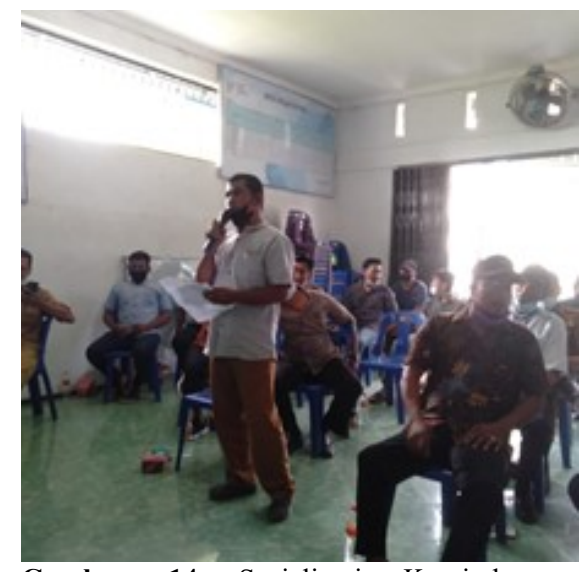

Gambar 14 Sosialisasi Keseimbangan Antara Pengelolalaan Operasional Bandar Udara dengan Kehidupan Masyarakat Sekitar dalam Perspektrif Hukum Lingkungan

b. Selama bandar udara berada di dekat desa kami, kami selalu terganggu baik itu siang dan malam karena kebisingan yang ditimbulkan oleh suara mesin pesawat yang melintas tepat di atas desa kami.

c. Pesawat yang melintas selalu membuat sinyal televisi hilang. Selain itu, kami juga merasa keselamatan kami terancam pada malam hari saat kami tidur karena kami takut pesawat tiba-tiba jatuh di desa kami.

d. Kami tidak diperbolehkan membangun bangunan lantai 3 dengan demikian perkembangan desa kami tidak meningkat.

e. Mekanisme laporan tuntutan Ganti Rugi apabila tidak ditanggapi oleh Pihak Bandara.

Setelah penyampaian sosialisasi keseimbangan antara pengelolalaan operasional bandar udara dengan kehidupan masyarakat sekitar dalam perspektrif hukum lingkungan oleh Ibu Dr. Novi Juli Rosani Zulkarneaen, S.H., M.H. Maka kegiatan terakhir adalah penutupan oleh ketua pelaksana dan foto bersama seperti diperlihatkan pada Gambar 15 dan Gambar 16.

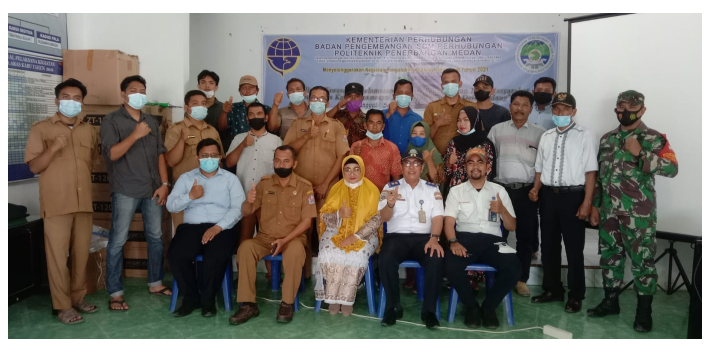

Gambar 15 Foto Bersinergi Bersama Narasumber dan Peserta

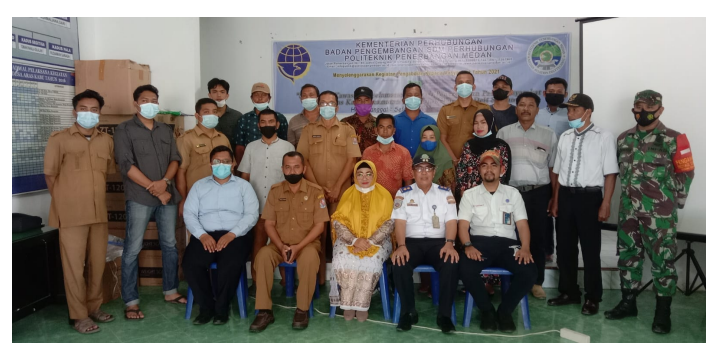

Gambar 16 Foto Bersama Narasumber dan Peserta

\section{SIMPULAN}

Berdasarkan hasil pemaparan materi oleh setiap narasumber maka dapat diperoleh beberapa kesimpulan. yaitu:

a. Politeknik Penerbangan Medan adalah salah satu perguruan tinggi kedinasan di bawah Kementerian Perhubungan. Berdasarkan UU No. 12 Tahun 2012, setiap dosen wajib melaksanakan kegiatan tridharma Perguruan Tinggi yang salah satunya adalah pengabdian kepada masyarakat. Dengan dilaksanakan kegiatan sosialisasi KKOP dimaksud, maka pemahaman masyarakat semakin tingggi.

b. Terdapat beberapa dampak positif keberadaan Bandar Udara Internasional Kualanamu bagi masyarakat Desa Aras Kabu, yaitu peningkatan serapan tenaga kerja, pembangunan fasilitas umum seperti puskesmas, masjid dan sebagainya, serta peningkatan usaha kecil menengah, peningkatan harga tanah dan lain-lain. Namun, dilain sisi juga terdapat dampak negatif, seperti seng/ atap rumah warga yang rusak, kebisingan, sinyal televise yang hilang dan lain-lain.

c. Masyarakat Desa Aras Kabu Kecamatan Beringin menerima himbauan agar tidak melakukan aktivitas yang dapat membahayakan operasi penerbangan sesuai dengan regulasi yang berlaku seperti menerbangkan drone dan layanglayang lebih dari $150 \mathrm{~m}$, menggunakan laser serta membakar sampah sehingga dapat mengganggu penghilatan ataupun pembacaan radar. Selain itu, masyarakat juga memahami untuk tidak mendirikan bangunan dengan ketinggian melebihi batas yang telah ditentukan.

d. Bandar udara di Indonesia berperan sebagai prasarana untuk pembangunan nasional, memperkokoh wawasan nusantara dan kedaulatan negara. Oleh 
karena itu, setiap warga negara wajib mendukung peran bandar udara sesuai dengan regulasi yang berlaku

\section{UCAPAN TERIMAKASIH}

Terimakasih penulis ucapkan kepada Lembaga Penelitian dan Pengabdian Politeknik Penerbangan Medan yang telah mendukung secara penuh kegiatan ini. Nomor Surat Keputusan SK.767/POLTEKBANG.MDN2021

\section{DAFTAR PUSTAKA}

ICAO. 1983. Part 6 Control of Obstacles.

Perhubungan. 2019. Standar Teknik Dan Operasional Peraturan Keselamatan Penerbangan Sipil Bagian 139 Volume 1 Bandar Udara. Vol. 1. Indonesia.

Perhubungan, Menteri. 2010. KM 11 Tahun 2010 Tentang Tatanan Kebandarudaraan Nasional. Indonesia.

President, and DPR. 2009. UU No.1 Tahun 2009 Tentang Penerbangan. Indonesia 